\title{
Promising Effect of Metallic Mordants on Colorimetric Physiognomy of Dyed Cotton Fabric Employing Banana (Musa Sapientum) Agricultural Waste
}

\author{
Md. Reazuddin Repon ${ }^{1}$, M Tauhidul Islam ${ }^{1,2, *}$, Md. Abdullah Al Mamun ${ }^{1}$ \\ ${ }^{1}$ Department of Textile Engineering, Mawlana Bhashani Science and Technology University, Bangladesh \\ ${ }^{2}$ Institute of Radiation and Polymer Technology, Bangladesh Atomic Energy Commission, Bangladesh
}

Copyright $(02016$ by authors, all rights reserved. Authors agree that this article remains permanently open access under the terms of the Creative Commons Attribution License 4.0 International License.

\begin{abstract}
This analysis intends to unveil the effect of metallic mordants on colorimetric properties of ecologically dyed cotton fabric using banana floral stem sap (BFS).Natural dye retrieved from banana floral stem by roller squeezer machine. Pre-mordanting action was performed by potassium alum, iron (II) sulphate, copper (II) sulphate and tin (II) chloride. Pre-mordanted specimens were dyed at $100^{\circ} \mathrm{C}$ for 60 minutes. Dye fiber binding actions was determined by FTIR-ATR spectra. Effect of metallic mordants were calculated using CIE $\mathrm{L}^{*} \mathrm{a}^{*} \mathrm{~b}^{*}$ color space in terms of colorimetric properties viz. color coordinates value i.e. lightness $\left(\mathrm{L}^{*}\right)$, redness $\left(\mathrm{a}^{*}\right)$, yellowness $\left(\mathrm{b}^{*}\right)$, color saturation $\left(\mathrm{C}^{*}\right)$ and hue angle $\left(\mathrm{h}^{0}\right)$; color strength $(\mathrm{K} / \mathrm{S})$ value; degree of color levelness and brightness index (BI). Though iron (II) sulphate treated samples exhibited height color saturation but uneven physiognomy was observed. Among them best colorimetric appearance yielded in case of alum. This reports forecast a sustainable pathway for effective utilization of agricultural waste i.e. banana floral stem sap for coloration of cotton fabric.
\end{abstract}

Keywords Eco-friendly Dyeing, Banana Floral Stem Sap, Natural Dyestuff, Metallic Mordants, Colorimetric Properties, Color Levelness

\section{Introduction}

The application of natural dyes for textile dyeing purposes declined to a great extent after the innovation of synthetic dyes in 1856 [1]. Synthetic dyes are widely available and have moderate to excellent color fastness properties and produce a wide diversity of colors. But discharged effluents from textile industries are severely endangering the human health and aquatic environment [2].

In this regards, the use of non-allergic, non-carcinogenic, non-toxic, very brilliant, rare color idea and eco-friendly natural dyes on textiles is a re-emerged soaring interest around the globe. It is a potential viable 'Green chemistry' for avoiding the uses of hazardous synthetic dyes for their various growing environmental and health concerns [3-5].

Natural dyes are safe and biodegradable in nature which can be obtained from different sources such as plants, insects/animals, microbes and minerals, renewable and sustainable bio resource products [4]. Moreover, they have many excellent functional properties such as mosquito repellency [6], antimicrobial and antiviral properties [3], flame retardency [7], UV protection properties [8], aroma properties [9], wound healing and anti-inflammatory properties [10], moisturizing and refreshing effects [11].

But tragically natural dyes show low exhaustion, poor to moderate wash and light fastness properties [12, 13]. Standardized method for dye extraction, color yield, complexity of dyeing process, limited shade, reproducible results; blending problems are also key constraints [14]. Most attempts for overcoming these problems involved the use of metallic salts as mordants. Commonly used mordants are aluminum potassium sulfate, stannous chloride, ferrous sulfate and copper sulfate. The metal ions can act as electron donor to form coordination bonds with the dye molecules.

Among numerous natural dye, banana floral stem sap is promising sustainable agricultural bio waste dye source. Banana plant parts viz. leaves engaged with cotton coloration [5]; pseudostem sap for mordant [15] and functional finishing [7] and pseudo stem fiber used for dye adsorbent [16]; banana peel for antibacterial activity and UV protection property of cotton fabrics [8] successfully. Dyeing time and temperature had optimized in our previous studies for cotton coloration using BFS, where lower depth of shade and limited color variety was observed [17, 18]. And till now no investigation had carried out to improve the dye fiber bond for boosting depth of shade and color variety of cotton coloration by BFS using metallic salts.

This present study attempts to extend the depth of shade 
and produce variety of color on coloration of cotton fabric using banana floral stem sap as natural dye together with various metallic mordants. Effective exploitation of bio-resource waste of banana plant was also aim of this work.

\section{Experimental}

\subsection{Materials and Methods}

\subsubsection{Materials}

Commercially scoured-bleached of $100 \%$ cotton knitted single jersey structure fabric having areal density of 175 grams per square meter was collected from "HI-FASHION COMPOSITE TEXTILES LTD”, Joydebpur, Gazipur, Bangladesh for this experiment. Table 1 depicts the color co-ordinates of the fabric used for this research work.

Table 1. Whiteness Index (WI), Brightness Index (BI) and Color co-ordinates value of scoured-bleached sample.

\begin{tabular}{|c|c|c|c|c|c|c|}
\hline WI & BI & L* & $a^{*}$ & $b^{*}$ & $c^{*}$ & H \\
\hline 68.38 & 94.19 & 93.68 & -0.30 & 3.67 & 3.68 & 94.74 \\
\hline
\end{tabular}

\subsubsection{Dyes \& Chemicals}

Banana floral Stem (Musa sapientum) was collected from Santosh area, Tangail-1902, Bangladesh. Potassium Alum $\left[\mathrm{Al}_{2} \mathrm{~K}_{2}\left(\mathrm{SO}_{4}\right)_{4}\right]$, Iron (II) sulfate heptahydrate $\left(\mathrm{FeSO}_{4} \cdot 7 \mathrm{H}_{2} \mathrm{O}\right)$, Copper (II) sulfate pentahydrate $\left(\mathrm{CuSO}_{4} \cdot 5 \mathrm{H}_{2} \mathrm{O}\right)$ and Stannous chloride pentahydrate $\left(\mathrm{SnCl}_{2} .5 \mathrm{H}_{2} \mathrm{O}\right)$ procured from merck, Germany. The ISO Standard soaping agent without optical brighter, James heal, England were used for removing unfixed dye. All chemicals were laboratory grade and employed without any purification.

\subsection{Methods}

\subsubsection{Sampling Plan}

Different samples are identified as below

Table 2. Sampling nomenclature

\begin{tabular}{|c|c|}
\hline Sample types & Identification \\
\hline Untreated /Control/ reference sample & $\mathrm{A}$ \\
\hline Potassium Alum treated sample & $\mathrm{B}$ \\
\hline Iron (II) sulfate treated sample & $\mathrm{C}$ \\
\hline Copper (II) sulfate treated sample & $\mathrm{D}$ \\
\hline Stannous chloride treated sample & $\mathrm{E}$ \\
\hline
\end{tabular}

\subsubsection{Natural Dye Extraction}

Dye used in this study was extracted according to our pervious investigations [17, 18]. Briefly, Banana (Musa sapientum) floral stems were detached from banana tree and washed. Fresh floral stem of the banana was cut into one meter pieces using cutlass and then pieces were sliced. Sap was extracted from floral stem by roller squeezer machine. Sap was filtrated by a nylon strainer and stored in plastic container. The sap was kept in a cool place and was prevented from sun rays to avoid evaporation and possible reaction for photo-catalytic degradation.

\subsubsection{Mordanting}

Cotton fabric samples were subjected to pre-mordanting with metallic mordants by $5 \mathrm{~g} / \mathrm{L}$ at $100^{\circ} \mathrm{C}$ for 60 minutes. After soaking overnight, the mordanted samples were squeezed and air dried in flat dryer machine (MESDAN, Italy). The material to liquor ration had kept 1:20 in pre-mordanting action $[17,18]$.

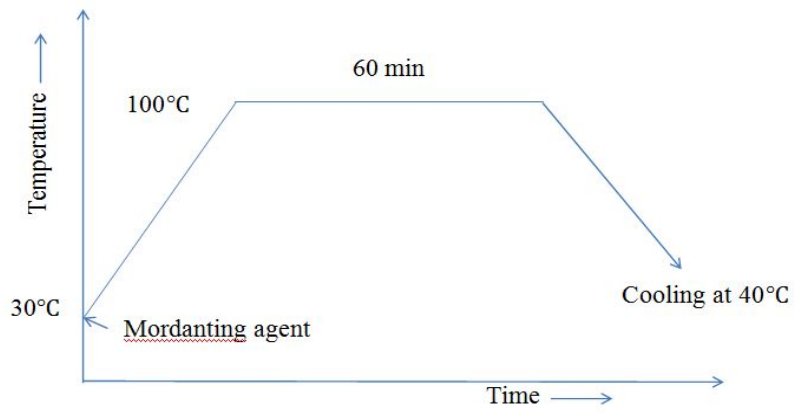

Figure 1. Process curve for pre-mordanting

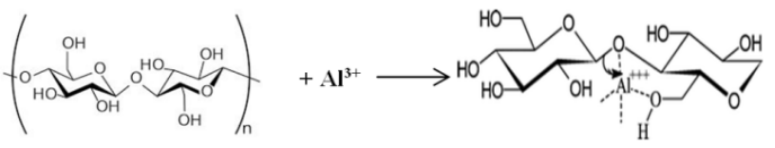

Figure 2. Co-ordination bond formation during mordanting of cotton with alum [30]

\subsubsection{Dyeing}

The dyeing action was ended according to our previous study $[17,18]$. Briefly, dyeing had carried out according to exhaust method by Infra-red lab sample dyeing machine (XIAMEN RAPID, China) at $100^{\circ} \mathrm{C}$ for 60 minutes. Then the dye bath was cooled at $40^{\circ} \mathrm{C}$. Samples were washed at room temperature and air dried in flat dryer machine (MESDAN, Italy).Then soaping was performed for removing unfixed dye from the fabric surface by $0.5 \mathrm{~g} / \mathrm{L}$ ISO standard soap at $80{ }^{\circ} \mathrm{C}$ for 10 minutes. For both dyeing and soaping, the material to liquor ration had kept 1:20.

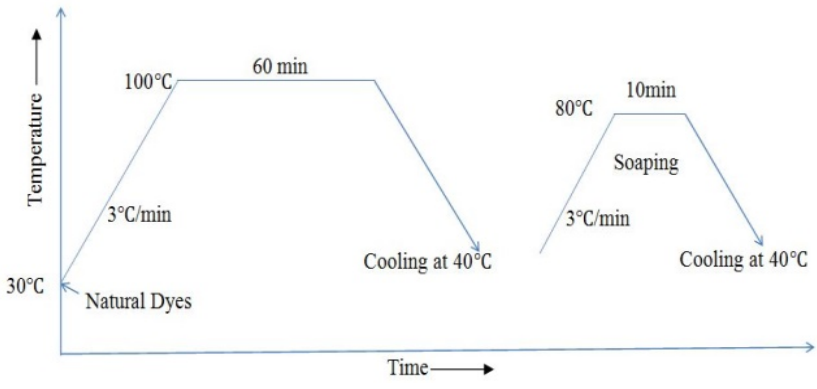

Figure 3. Dyeing Curve

\subsubsection{FTIR-ATR Spectra}

FTIR-ATR spectra of scoured bleached cotton and dyed specimens were determined using FTIR spectrophotometer (PerkinElmer Spectrum Two, UK). Specimens were directly 
fitted on the respective place of Universal ATR of the machine for dye-fiber bonding characteristics evaluation.

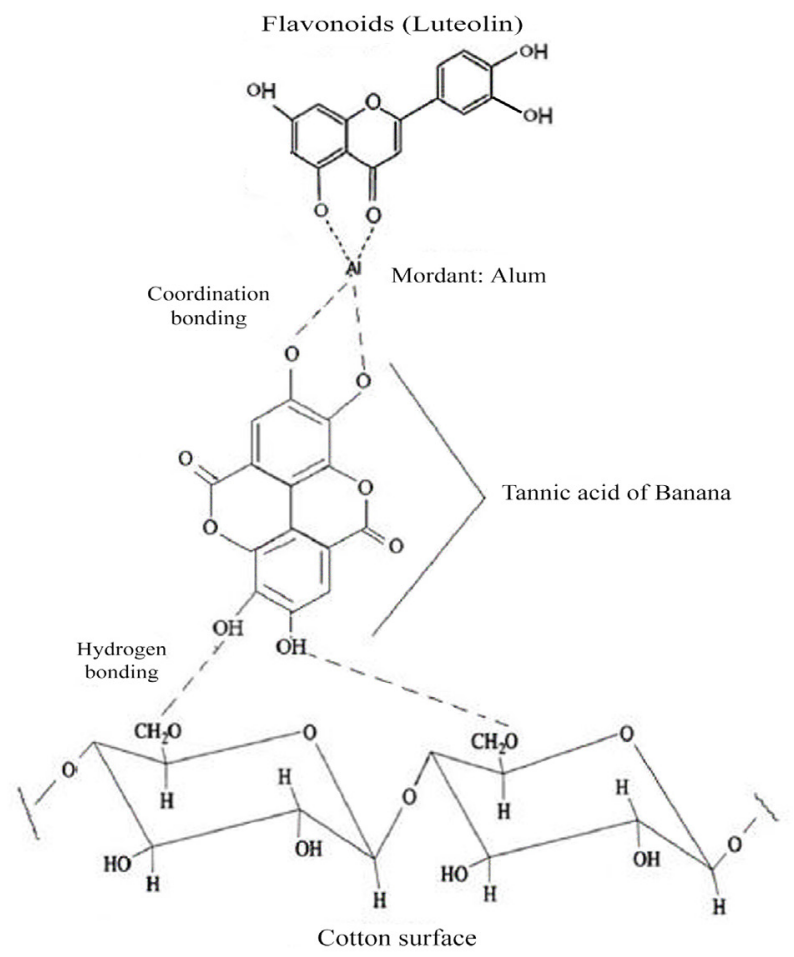

Figure 4. Binding among tannic acid, flavonoids (Luteolin) of banana floral stem sap with cotton surface [19,27].

\subsubsection{Determination of Color Coordinates Value}

The color coordinates of the dyed samples were determined based on the CIE Lab system via dual beam reflectance Data-color Spectroflash (SF 650X, USA) keeping the setting: Illuminant D65, Medium area view, Specular included and CIE 1964 supple-mental standard observer $\left(10^{\circ}\right.$ observer). Each sample was folded twice to give an opaque view with four plies and the color coordinates value was measured automatically $[17,18]$.

\subsubsection{Determination of Degree of Color Levelness}

The degree of levelness was measured according to Uddin, Mohammad Gias (2015) [20]. Briefly, color difference, $\Delta \mathrm{E}$ value was measured by equation 1 .

$$
\Delta \mathrm{E}=\sqrt{\left(\Delta \mathrm{L}^{*}\right)^{2}+\left(\Delta \mathrm{a}^{*}\right)^{2}+\left(\Delta \mathrm{b}^{*}\right)^{2}}
$$

Where, $\Delta \mathrm{L}^{*}=\mathrm{L}^{*}$ sample $-\mathrm{L}^{*}$ standard, $\Delta \mathrm{a}^{*}=\mathrm{a}^{*}$ sample $\mathrm{a}^{*}$ standard and $\Delta \mathrm{b}^{*}=\mathrm{b}^{*}$ sample $-\mathrm{b}^{*}$ standard

\subsubsection{Determination of Color Strength}

The color strength (K/S value) of the dyed samples was measured by datacolor spectrophotometer based on KubelkaMunk theory (Equation 2) [21].

$$
\frac{\mathrm{K}}{\mathrm{S}}=\frac{(1-\mathrm{R})^{2}}{2 \mathrm{R}}
$$

Where, $\mathrm{R}=$ Reflectance of an incident light from the dyed material, $\mathrm{K}=$ Absorption and $\mathrm{S}=$ Scattering coefficient of the dyed fabric. The $\mathrm{K} / \mathrm{S}$ values were determined at the maximum absorption wavelength $\left(\lambda_{\max }=360\right)$ at which reflectance value is lowest.

\subsubsection{Determination of Brightness Index}

Brightness index was measured as per the standard (ISO-2470-1977) [20] method using equation 3.

$$
\text { Refletance value of the substrate at } 360 \mathrm{~nm}
$$

Brightness index =

$\overline{\text { Reflectance value of white diffuser or white tile at } 360 \mathrm{~nm}}$

\section{Results and Discussion}

\subsection{FTIR-ATR Characterization}

Figure 5 represents the IR spectra of scoured bleached (1) and dyed specimen employing BFS (2). The peaks value of spectra assigned as:

- Broad band at $3335.4 \mathrm{~cm}-1$ attributed to $-\mathrm{OH}$ stretching vibration for $\mathrm{H}$ bonded $\mathrm{H} 2 \mathrm{O}$ uptake [23].

- Two peaks at $2915.2 \mathrm{~cm}-1$ and $2858.6 \mathrm{~cm}-1$ corresponds asymmetric and symmetric stretching of long methylene (-CH2-) chain for residual wax on cotton [24].

- For adsorbed $\mathrm{H} 2 \mathrm{O}$ into the fabric specimen, peaks appeared at $1638 \mathrm{~cm}-1$ [25]

- Peak observed at $1423 \mathrm{~cm}-1$ which attributed for $\mathrm{C}-\mathrm{H}$ wagging of carbohydrate and lignin $[24,25]$

- For presence of the band at $1323 \mathrm{~cm}-1$ endorsed for lignin [26].

- Both peaks at $1153 \mathrm{~cm}-1$ and $1109 \mathrm{~cm}-1$ corresponds for asymmetric ether linkage (-C-O-C-) [24].

- For cellulose, hemicellulose and minor lignin contribution Spectra (1) \& (2) exhibited strong band at $1028.3 \mathrm{~cm}-1$ due to $\mathrm{C}-\mathrm{O}-\mathrm{C}$ symmetric stretching di-alkyl ether linkages and $\mathrm{C}-\mathrm{O}$ stretching vibration [26].

- $\quad$ Peak at $898 \mathrm{~cm}-1$ attributes for $\beta$ glycocidic likage and asymmetric out of phase ring stretch of $\mathrm{C}_{1}-\mathrm{O}-\mathrm{C}_{4}$ [23].

For dyed cotton with BFS (2), 4 major changes appeared at peaks 882.83,1000, 1056.6, 1173.7 and $1396 \mathrm{~cm}-1$ respectively, which endrose the investigation of Basak et al. (2015) [23], Paul et al. (2013) [15] and Monteiro et al. (2014) [27]. Due the presence of inorganic salts into BFS peaks exhibited at 873,1000 and $1176 \mathrm{~cm}-1$ for potassium chloride, sodium phosphate and magnesium chloride respectively [28, 29]. Peaks at 1056.6 correspond $\mathrm{C}-\mathrm{H}$ and $\mathrm{C}-\mathrm{O}$ deformation band [25] and $1396 \mathrm{~cm}-1$ was responsible for $\mathrm{CH}$ deformation of - $\mathrm{CH} 2-$ [26]. For BFS stronger band seen at $1028.3,1109,1161.6,1323.2$ and $1638.4 \mathrm{~cm}-1$ for spectra of dyed fabric (2) than Control (1) by waning over all transmittance \% due to presence of tannin, flavonoid, lignin, etc (Figure 4) [27]. 


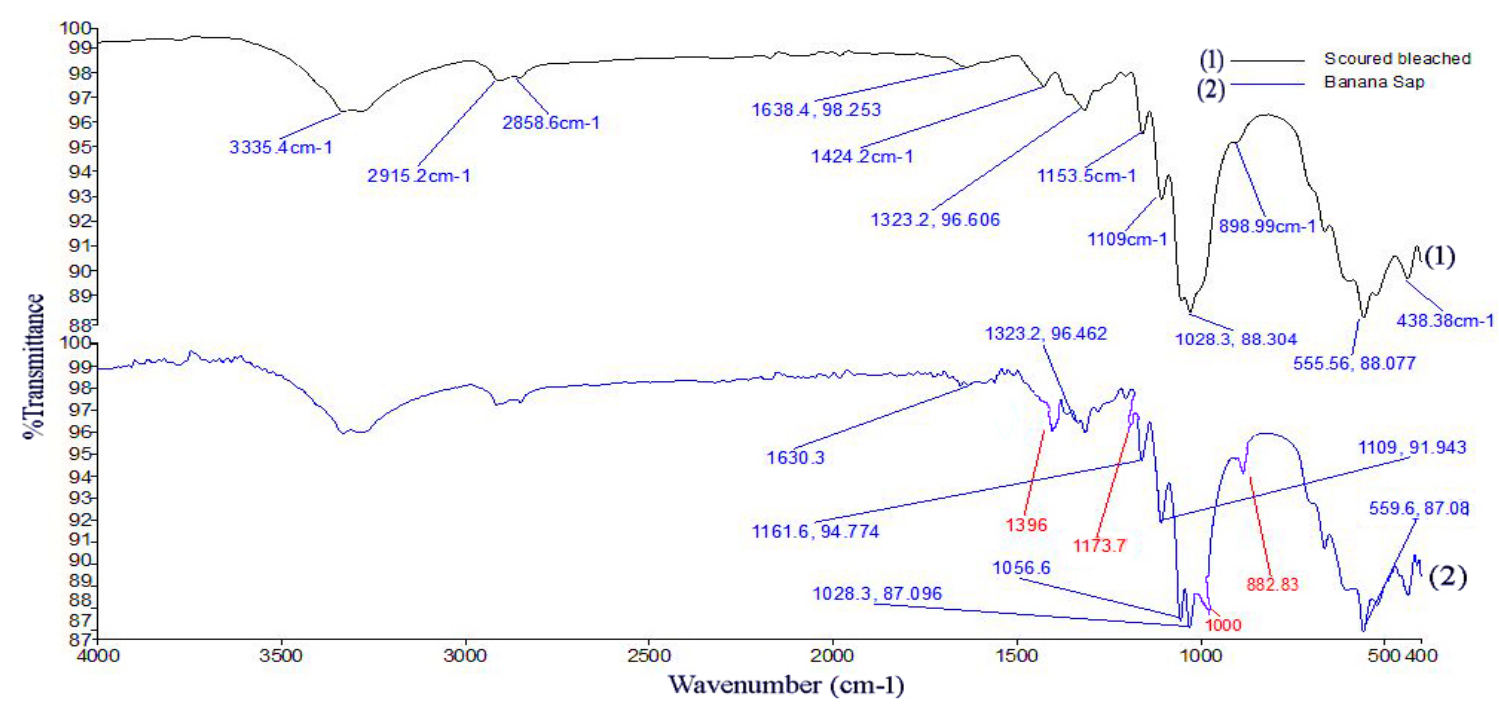

Figure 5. FTIR-ATR Spectra of scoured bleached cotton (1) and dyed cotton using banana sap (2).

Table 3. Color co-ordinate values

\begin{tabular}{|c|c|c|c|c|c|c|}
\hline Samples types & $\mathrm{L}^{*}$ & $\mathrm{a}^{*}$ & $\mathrm{~b}^{*}$ & $\mathrm{C}^{*}$ & $\mathrm{H}^{0}$ & Photograph \\
\hline $\mathrm{A}$ & 80.75 & 3.97 & 12.04 & 12.68 & 71.75 & \\
\hline $\mathrm{B}$ & 77.26 & 5.04 & 11.70 & 12.74 & 66.71 & \\
\hline $\mathrm{C}$ & 71.89 & 4.83 & 12.81 & 13.69 & 69.34 & \\
\hline $\mathrm{D}$ & 73.14 & 4.63 & 12.93 & 13.74 & 70.28 & \\
\hline $\mathrm{E}$ & 75.55 & 5.09 & 13.17 & 14.12 & 68.88 & \\
\hline
\end{tabular}

\subsection{Color Co-ordinate Values of Dyed Specimens}

Table 3 depicts the CIELAB color co-ordinates of dyed specimens.

Regarding lightness $\left(\mathrm{L}^{*}\right)$, the samples orders were found as $\mathrm{A}>\mathrm{B}>\mathrm{E}>\mathrm{D}>\mathrm{C}$. Minimum $\mathrm{L}^{*} 71.89$ noticed for $\mathrm{C}$ i.e. maximum darkness. B, C, D and $\mathrm{E}$ were $4.32 \%, 10.97 \%$, $9.42 \%$ and $6.44 \%$ respectively darker than $\mathrm{A}$. Regarding redness $\left(a^{*}\right)$ orders of samples were found $E>B>C>D>A$. The sample $\mathrm{E}$ was reddish and $\mathrm{A}$ was greenish amongst all. $\mathrm{B}, \mathrm{C}, \mathrm{D}$ and $\mathrm{E}$ samples were $26.95 \%, 21.66 \%, 16.62 \%$, and $28.21 \%$ redder than control sample. Concerning yellowness $\left(b^{*}\right)$ orders of samples were found $\mathrm{E}>\mathrm{D}>\mathrm{C}>\mathrm{A}>\mathrm{B}$. Among them $\mathrm{E}$ showed maximum and $\mathrm{B}$ showed minimum yellowness. The sample C, D and F were $6.40 \%, 7.39 \%$ and $9.39 \%$ yellower than reference sample. But B was $2.82 \%$ bluer than $\mathrm{A}$. The orders of color saturation $\left(\mathrm{c}^{*}\right)$ of samples were found to be $\mathrm{E}>\mathrm{D}>\mathrm{C}>\mathrm{B}>\mathrm{A}$. $\mathrm{E}$ had highest and $\mathrm{A}$ had lowest color saturation among all samples. The Sample B, C, $\mathrm{D}$ and $\mathrm{E}$ was $0.47 \%, 7.97 \%, 8.36 \%$ and $11.36 \%$ more color saturation than untreated sample correspondingly. For hue angle $\left(h^{0}\right)$ orders of samples were found $A>D>C>E>B$.

The highest hue angle for $\mathrm{A}$ and lowest for $\mathrm{B}$ was observed. The hue angle of sample B, C, D and E were
$7.02 \%, 3.36 \%, 2.05 \%$ and $4.0 \%$ lower than control sample respectively.

BFS comprises of many organic and inorganic compound [27]. From maximum absorption wavelength $(\lambda \max =350 \mathrm{~nm})$ of UV spectra it can be presumed that the color appeared in the dyed samples is liable for flavonoids [32]. The presence of hydroxyl and carbonyl groups in the dye and cellulose structure is capable to form complex by chelating via co-ordination bond with positively charged metals. Some alteration appeared in color coordinates value for mordanted dyed specimens as compared (B, C, D, and E) with control sample (A). Hence, one molecule of metal can form a bond with two or more molecules of dye and fiber simultaneously according to their co-ordination numbers. More color saturation observed for iron mordanted samples as it has coordination number 6 and has stronger capability of dye-mordant-fiber interactions than copper, tin and alum respectively. Color saturation $\left(\mathrm{c}^{*}\right)$ is inversely proportional with lightness $\left(\mathrm{L}^{*}\right)$. Alum mordanted specimens exhibited higher L* as it block dye molecules by bonding with more with dye then fiber molecule. The alteration of yellowness and redness had followed same fashion [30, 31].

\subsection{Degree of Color Levelness}


The orders average color difference value of samples were found $\mathrm{C}>\mathrm{D}>\mathrm{E}>\mathrm{B}>\mathrm{A}$ (Table 4). Though, there was difference in average color difference value but all samples showed excellent color levelness.

Homogeneity of dye molecule distribution onto the fiber surface essentially indicates the levelness of color. The unmordanted dyed samples showed better levelness due to higher homogeneous dye spreading for dye-fiber interaction. All types of mordanted colored specimens exhibited poor levelness than control sample for simultaneous dye-mordants and fiber mordants interaction [30]. Iron has stronger coordination linkage formation capability due to having 6 coordination numbers than other metals. Iron salts can form a complex one site with the fiber and other site with the dye and hence slightly greater color difference appeared. The order of strength of coordination bond formation among dye, mordants and cotton fiber interaction is iron $>$ copper $>$ tin $>$ alum which bolster accessed values [31].

\subsection{Color Strength (K/S) Value}

The figure 2 illustrates the effect of metallic mordants on dyed materials. The dye fixation increased due to pre-mordanting action with metallic mordants. The color strength value of samples were found $\mathrm{C}>\mathrm{D}>\mathrm{E}>\mathrm{B}>\mathrm{A}$ orderly. The maximum color strength 1.10 was yield for $\mathrm{C}$ at maximum wavelength $360 \mathrm{~nm}$. The $\mathrm{K} / \mathrm{S}$ value of $\mathrm{B}, \mathrm{C}, \mathrm{D}$ and E samples was $26.15 \%, 69.23 \%, 58.46 \%$, and $41.54 \%$ higher than reference sample.

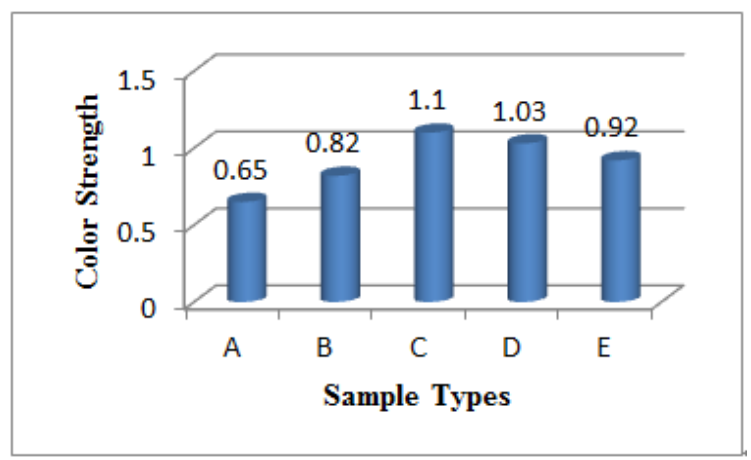

Figure 6. Color Strength $(\mathrm{K} / \mathrm{S})$ value

Iron and copper treated samples exhibited the highest $\mathrm{K} / \mathrm{S}$ values. Both these metals have excellent ability to form coordination complexes by readily chelating with the dye molecule. As the coordination numbers of copper and iron are 4 and 6respectively, some co-ordination sites stayed vacant when they interacted with the cotton. Thus these metals can form a complex simultaneously with the cotton in one site and with the dye (tannin, flavonoids)on the other site that leads high dye uptake. In case of cotton, iron exhibited stronger fabric-mordants-dye interaction than copper [30]. Alum and tin are liable for strong binding with dye but not with fiber. They block the dye and reduce its interaction with fiber. Thus lower K/S value appeared as they form weaker co-ordination linkages with dye molecule [31].

\subsection{Brightness Index Value}

The figure 3 depicts the effect of metallic mordants on brightness index of the sample. Regarding brightness index value, the samples orders were found as $A>B>E>D>C$. The highest brightness index value was 50.58 for untreated as it involved with dye-fiber interaction only. The samples B, C, $\mathrm{D}$ and $\mathrm{E}$ showed $14.97 \%, 30.03 \%, 22.44 \%$ and $19.73 \%$ lower brightness index than control sample. All mordanted samples exhibited lower brightness index value as they strongly involved with dye-mordants-fiber interaction. Lowest value yielded 35.39 for iron as it involved with stronger cotton-mordants-dye interactions than others.

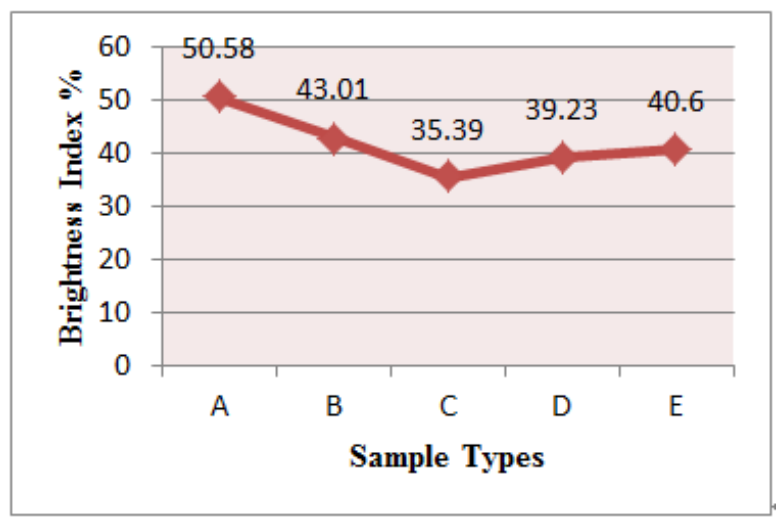

Figure 7. Brightness index $\%$ value

Among all mordants, alum displayed brightest appearance [32]. Tin also exhibited lighter shade but it may reduce the hand feel properties [33].

Table 4. Degree of color levelness.

\begin{tabular}{|c|c|c|c|c|c|c|c|c|c|c|c|}
\hline \multirow{3}{*}{ Time } & \multicolumn{10}{|c|}{$\Delta \mathrm{E}$ values of dyed samples } & \multirow{3}{*}{$\begin{array}{c}\text { Average } \\
\Delta \mathrm{E}\end{array}$} \\
\hline & \multirow{2}{*}{$\mathrm{R}-1$} & $\mathrm{R}-2$ & $\mathrm{R}-3$ & $\mathrm{R}-4$ & $\mathrm{R}-5$ & $\mathrm{R}-6$ & $\mathrm{R}-7$ & $\mathrm{R}-8$ & $\mathrm{R}-9$ & $\mathrm{R}-10$ & \\
\hline & & \multicolumn{9}{|c|}{ Batch readings } & \\
\hline A & \multirow{5}{*}{ Standard } & 0.292 & 0.038 & 0.067 & 0.029 & 0.072 & 0.047 & 0.048 & 0.017 & 0.014 & 0.069 \\
\hline B & & 0.304 & 0.075 & 0.052 & 0.133 & 0.088 & 0.063 & 0.039 & 0.068 & 0.026 & 0.094 \\
\hline $\mathrm{C}$ & & 0.507 & 0.363 & 0.060 & 0.026 & 0.048 & 0.038 & 0.070 & 0.045 & 0.062 & 0.135 \\
\hline $\mathrm{D}$ & & 0.375 & 0.209 & 0.154 & 0.096 & 0.089 & 0.059 & 0.045 & 0.051 & 0.067 & 0.127 \\
\hline E & & 0.089 & 0.118 & 0.179 & 0.243 & 0.037 & 0.138 & 0.057 & 0.146 & 0.094 & 0.122 \\
\hline
\end{tabular}




\section{Conclusions}

Promising effect of metallic mordants on colorimetric property of dyed cotton fabric was accessed employing banana floral stem sap. Dye fixation rate was increased due pre-treatment with metallic mordants. From measured colorimetric of value it is concluded that limited shade was overcome by treating with metallic mordants. Medium depth of shade was appeared for using of potassium alum, iron (II) sulphate, copper (II) sulphate, tin (II) chloride. The order of strength of coordination bond formation among dye, mordants and cotton fiber interaction is iron $>$ copper $>$ tin $>$ alum. Alum has homogenous BFS dye molecule distribution ability onto cotton surface. Finally, extension of color variety and depth of shade achieved during coloration of cotton fabric using banana floral stem sap through effective exploitation of banana agricultural waste.

\section{REFERENCES}

[1] Saravanan P. and Chandramohan G., "Dyeing of silk with Eco-Friendly Natural Dye Obtained from Barks of Ficus Religiosa".Universal J. of Env. Res. and Tech., Vol.1; No.3, pp. 268-273, 2011

[2] Bhuiyan, M. A. R. (2015). Treatment of textile effluent by radiation for dyeing and irrigation purpose (Doctoral dissertation, University of Dhaka).

[3] Sasmita Baliarsingh, Jyotsna rani Jena, Trupti Das, Nalin B. Das, "Role of cationic and anionic surfactants in textile dyeing with naturaldyes extracted from waste plant materials and their potential antimicrobial properties". Industrial Crops and Products, Vol. 50, pp. 618-624, 2013.

[4] Samanta, A.K., Agarwal, P. "Application of natural dyes on textiles”. Indian J. Fibre Text. Res., Vol. 34,pp. 384-399, 2009.

[5] Salah. M. Saleh, Yasser A. Abd-El-Hady, Kh. El-Badry. "Eco-friendly Dyeing of Cotton Fabric with Natural Colorants Extracted from Banana Leaves". International Journal of Textile Science, Vol. 2,No. 2; pp. 21-25, 2013.

[6] Specos MM, Gracia JJ, Tornsullo J, Marino P, Vechia MD, Tesoriero MV, Hermisa LG., "Microencapsulated citronella oil for mosquito repellent finishing of cotton textiles". R Soc Trop Med Hyg, Vol. 104,pp. 653-658, 2010.

[7] Basak S, Saxena S, Chattopadhyay SK, Narkar R and Mahangade R. "Banana pseudostem sap: A waste plant resource for making thermally stable cellulosic substrate". Journal of Industrial Textile, Vol. 0, No. 00, pp. 1-21, 2015.

[8] Salah SM. "Antibacterial activity and UV protection property of some Egyptian cotton fabrics treated with the aquous extract of banana peel". International Journal of Clothing Science, Vol. 1, No. 1, pp.1-6, 2012.

[9] Banupriya J, Maheshwari V. "Effects of Aromal Finish by
Herbal and Conventional Methods on Woven Fabrics". J Textile Sci Eng., Vol. 3, p. 138, 2013.

[10] Srivastava A, Singh TG. "Utilisation of aloe vera for dyeing natural fabrics”. Asian J Home Sci., Vol. 6, p.1-4, 2011.

[11] Varun SK. "An evaluation of aroma imparted by cotton fabrics dyed by natural colourants". BMC Dermatol, Vol. 4, pp.1-15, 2004.

[12] Young-Hee Lee, "Dyeing, Fastness, and Deodorizing Properties of Cotton, Silk, and Wool Fabrics Dyed with Coffee Sludge (Coffeaarabica L.) Extract". Journal of Applied Polymer Science, Vol. 103, pp. 251-257, 2007.

[13] Saima Umbreen, Shaukat Ali, Tanveer Hussain and Rakhshanda Nawaz. "Dyeing Properties of Natural Dyes Extracted from Turmeric and their Comparison with Reactive Dyeing”. RJTA, Vol.12, No. 4; pp.1-11, 2008.

[14] SachanKiran, Kapoor VP. "Optimization of extraction and dyeing condition for traditional Turmeric dye". Indian Journal of Traditional Knowledge, Vol. 6, No. 2, pp. 270-278, 2005.

[15] Paul V., Kanny K. \& Redhi G.G., "Formulation of a novel bio-resin from banana sap". Industrial Crops and Products, Vol. 43, pp. 496- 505, 2013

[16] Shuaibing, Z.M.Z.S.L. and Qihua, Z., "Adsorption of dye wastewater by banana peel powder immobilized by sodium alginate". Chinese Journal of Environmental Engineering, Vol.6, p.036, 2013.

[17] Md. Reazuddin Repon , Md. Abdullah Al Mamun , M Tauhidul Islam. Optimization of Dyeing Time of Eco-friendly Cotton Coloration Using Banana (Musa Sapientum) Floral Stem Sap. Chemical and Materials Engineering, Vol. 4 No. 2, pp. 26 - 31. 2016.

[18] Md. Reazuddin Repon, Md. Abdullah Al Mamun, M Tauhidul Islam. Eco-friendly Cotton Coloration Using Banana (Musa Sapientum ) Waste: Optimization of Dyeing Temperature, Universal Journal of Engineering Science, Vol. 4 No. 1, pp. 14-20. 2016

[19] Sinha, K., Aikat, K., Das, P., \& Datta, S. (2016). Dyeing of Modified Cotton Fiber with Natural Terminalia arjuna Dye Optimization of Dyeing Parameters Using Response Surface Methodology, Vol. 35 No. 3, 719-728.

[20] Uddin, Mohammad Gias. "Study on the color levelness of silk fabric dyed with vegetable dyes." Sustainable Chemical Processes 3.1 (2015): 1-4.

[21] Mcdonald, R (Ed.). (1997). Color physics for industry (2nd ed.). Soc. Bradford: Dyers and Colorist

[22] Paper and board: Measurement of diffused blue reflectance factor (ISO-brightness) ISO 2469 \& 2470, 2nd International Prganization for Standaradization, Switzerland, 1977.

[23] Basak, S., Samanta, K., Saxena, S., Chattopadhyay, S. K., Narkar, R., Mahangade, R., \& Hadge, G. B., "Flame resistant cellulosic substrate using banana pseudostem sap". Polish Journal of Chemical Technology, Vol.17, No.1, pp.123-133, 2015.

[24] Chung, C., Lee, M., \& Choe, E. K., "Characterization of cotton fabric scouring by FT-IR ATR spectroscopy". Carbohydrate Polymers, Vol. 58, No.4, pp. 417-420, 2004. 
[25] Bilba, K., Arsene, M. A., \&Ouensanga, A., "Study of banana and coconut fibers: Botanical composition, thermal degradation and textural observations". Bioresource technology, Vol. 98, No.1, pp.58-68, 2007.

[26] Ibrahim, M. M., Dufresne, A., El-Zawawy, W. K., \& Agblevor, F. A., "Banana fibers and microfibrils as lignocellulosic reinforcements in polymer composites". Carbohydrate polymers, Vol. 81, No. 4, pp.811-819, 2010.

[27] Monteiro, S. N., Margem, F. M., Loiola, R. L., de Assis, F. S., \& Oliveira, M. P., "Characterization of banana fibers functional groups by infrared spectroscopy". In Materials Science Forum, Vol. 775, pp. 250-254, 2014.

[28] Miller, A.F. \& Wilkins, H.C., "Infrared spectra and characteristic frequencies of inorganic ions". Anal. Chem., Vol. 24, No. 8, pp.12530-1294, 1952.

[29] Honeycutt, W., Xing, B., Mcdowell, W.R., Pellechias, J.P. \&
Zhang, T., "Solid state fourier transform infrared and31P nuclear magnetic resonance spectral features of phosphate compound”. Soil Sci., Vol. 172, No. 7, pp.501-515, 2007.

[30] Uddin Mohammad Gias, "Extraction of eco-friendly natural dyes from mango leaves and their application on silk fabric". Textiles and Clothing Sustainability, Vol.1, No.7, 2015.

[31] Bhattacharya, S. D., \& Shah, A. K., "Metal ion effect on dyeing of wool fabric with catechu". Coloration Technology, Vol.116, No.1, pp.10-12, 2000.

[32] Ding, Yi. "A Comparison of Mordant Dyes and Natural Dyes in Dyeing Cotton Fabric",2013. Retrieved from http://repository.lib.ncsu.edu/ir/handle/1840.16/8851 accessed on 28-May-16 at 14:48.

[33] Cardon, Dominique, "Natural Dyes: Sources, Tradition, Technology and Science. London : Archetype Pulications Ltd., 2007. 